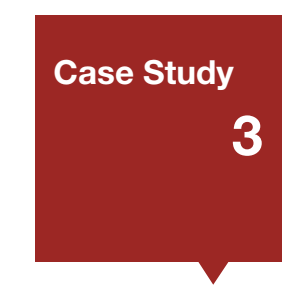

\title{
Brexit - and its potential impact for Open Access in the UK
}

\author{
Author: Paul Ayris - Pro-Vice-Provost (UCL Library Services), \\ Co-Chair of the LERU INFO Community (League of European \\ Research Universities) \& Adviser to the LIBER Board (Association \\ of European Research Libraries) \\ Email: p.ayris@ucl.ac.uk
}

\subsection{ESTABLISHING THE CASE}

In the Referendum of $2016^{1}$, the UK's decision to leave the EU has caused both delight and consternation. A fundamental driver for that result was the perception that the UK needed to achieve greater autonomy. In some quarters, this has led to loud calls for individual autonomy. London Mayor Sadiq Khan wants London to be given more autonomy from central government following the UK's vote ... to leave the European Union, saying that the city needs to "take back control." '2 Autonomy is a powerful and emotive word. It is important to note that autonomy is not the same as independence. As the Mayor has also said: "I want to send a particular message to the almost one million Europeans living in London, who make a huge contribution to our city - working hard, paying taxes and contributing to our civic and cultural life. You are welcome here. We value the enormous contribution you make to our city and that will not change as a result of this referendum. ${ }^{3}$ Nonetheless, the Mayor seeks to establish a new agenda for London in a Brexit world: 'It's not simply a state of mind or an attitude - it's what we are: open for talent, for business, for investment.' ${ }^{4}$

If London is open, what does that mean for universities and their activities? First, it would be helpful to tie down what the role of the university in the early $21^{\text {st }}$ century is. Professor Ronald Barnett at the UCL Institute of Education has said, 'We are now coming to have a sense that what it is to be a university in the 21 st century necessarily includes a positive orientation to the world, in all of its aspects. The university - as an idea - is not only networked across the world, not only active in many countries, but takes up a positive stance towards the world. Indeed, it has a care for the world, wanting to play its part in helping to improve the world. ${ }^{5}$ That is a very helpful discussion and offers much in terms of understanding the possible consequences of Brexit.

Many commentators have reacted with fear and alarm to the Brexit vote. Immigration is seen by some as the major issue and as a driver for the 'No' vote in the Referendum. Others note the impact of Brexit on exchange rates, and the perceived damage were the UK to leave the Single Market. ${ }^{6}$ For universities, there are enormous concerns over the possible loss of EU funding in Horizon 2020, the ability of UK universities to recruit overseas students and to retain its EU workforce. ${ }^{7}$ Universities UK has highlighted a key concern as: 'In terms of recruiting EU staff in the longer term, any changes will depend on the kind of relationship

Electoral Commission: http://www.electoralcommission.org.uk/find-information-by-subject/elections-and-referendums/past-elections-andreferendums/eu-referendum/electorate-and-count-information; last accessed 3/1/17.

Business Insider UK: http://uk.businessinsider.com/sadiq-khan-speech-on-london-independence-after-brexit-and-the-eu-referendum-2016-6; last accessed 3/1/17

Independent: http://www.independent.co.uk/news/uk/sadiq-khans-brexit-eu-referendum-response-in-full-there-is-no-need-to-panic-a7100071 . html; last accessed 3/1/17

Financial Times: https://www.ft.com/content/d32b1a42-7a5b-11e6-ae24-f193b105145e; last accessed 3/1/17.

Barnett, R, 24 June 2016, EU referendum: will UK HE become less global, more parochial? THE blog: https://www.timeshighereducation.com/ blog/eu-referendum-will-uk-he-become-less-global-more-parochial; last accessed 3/1/17.

BBC: http://www.bbc.co.uk/news/uk-politics-32810887 gives an overview of current issues at the end of 2016; last accessed 3/1/17.

UUK: http://www.universitiesuk.ac.uk/policy-and-analysis/brexit/Pages/brexit-faqs.aspx; last accessed 3/1/17. 
the UK negotiates with the EU. However, UUK is committed to highlighting the value of all EU staff, including researchers, scientists and academics, and is urging the UK government to guarantee that those currently working at UK universities can continue to do so after the UK exits the EU.'

Clearly, the current situation poses threats. However, the purpose of this article is to suggest that Brexit is not simply a threat, but also an opportunity. A recent article in Insights suggested that Brexit presented opportunities for commercial publishing, 8 '... where some publishers see adversity, others see possibility. opportunities for commercial publishing, ${ }^{8}$.... where some publishers see adversity, others see possibility.
While there has been much hand-wringing about economic fallout, nearly half of all publishers see Brexit as an opportunity to make money on exports ...' The words of Sadiq Khan on the future of London are important here - 'it's what we are: open for talent, for business, for investment.' The emphasis is on the word 'open', and it is the argument of this article that Brexit presents not only challenges but also rea opportunities for the UK and Open Access, not in terms of autonomy but of freedom - the freedom to innovate and to devise new models for the dissemination of scholarly outputs. These are core values of the Open Access movement and 2017 presents the opportunity to invest time and effort to deliver on them.

\subsection{DELIVERING THE GOODS}

How has the UK contributed to this vision for an Open Access future? Is it an independent view or one shaped in collaboration with others? What challenges lie ahead for the UK in developing its Open Access position and presence? A study of four themes can help tease out answers to these questions: Open Access policies and mandates, EU copyright reform, new Open Access publishing models and Open Science.

\section{Policies and mandates}

Brexit means that the UK will leave membership of the European Union, not that it will be leaving Europe. 'Brexit means Brexit', but the nature of the future relationship remains to be worked out. However, Open Access is a European - and indeed a global - agenda, not solely a matter for the EU. Europe is awash with Open Access infrastructure. As of 3 January 2017, OpenDOAR listed 3,285 Open Access repositories. $45.2 \%$ of these are based in Europe. Looking at the breakdown of repositories by country worldwide, the top 9 countries with a repository presence are as follows:

\begin{tabular}{|l|l|l|}
\hline Country & $\%$ & No. \\
\hline United States & 15 & 493 \\
\hline United Kingdom & 7.6 & 250 \\
\hline Japan & 6.4 & 211 \\
\hline Germany & 5.9 & 193 \\
\hline Spain & 3.8 & 124 \\
\hline France & 3.6 & 119 \\
\hline Italy & 3.3 & 110 \\
\hline Brazil & 2.8 & 91 \\
\hline Poland & 2.7 & 90 \\
\hline Other & 48.8 & 1604 \\
\hline
\end{tabular}

The UK does well in terms of its place in this particular league table, coming second overall and ahead of any other European nation.

Arguably, the drive towards Open Access in the UK has been driven by UK funder mandates, by the Finch Review and by the recent HEFCE Open Access requirement for REF2020. Research-intensive universities are on the ball in supporting their researchers in meeting the requirements of Open Access funder policies. UCL (University College London), for example, lists 39 funder policies on its website, ${ }^{9}$ only 4 of which UCL (University College London), for example, lists 39 funder policies on its website, ${ }^{9}$ only 4 of which
are linked directly to the European Union. It should be noted, however, that these European funders are are linked directly to the European Union. It should be noted, however, that these European funders are

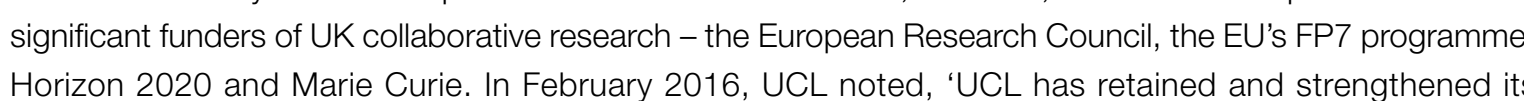
position as the top performing university in Europe in the major EU funding scheme Horizon 2020, securing more than 6103 million so awarded nine highly prestigious European Research Council (ERC) Consolidator Grants, totalling around $€ 15$ million and placing the university as the second-placed higher education institution in Europe for the number of grant awards under this scheme. UCL has also been awarded 27 Marie Curie International Fellowships, worth around $€ 6$ million. ${ }^{10}$ Clearly, loss of EU research funding will have a major impact on the ability of research-intensive universities to undertake research and so to disseminate the results of that research activity as Open Access outputs. As Universities UK has stated: 'UUK will make the case to government of the importance and impact of our strong research collaboration with European partners, highlighting how EU programmes play a central role in supporting this. ${ }^{11}$

Funding is a serious issue, but in other areas the UK has made a significant contribution to the global OA debate. The Finch Report, ${ }^{12}$ accepted by Government in July 2012, was key in determining a public policy position in the UK on Open Access. On 16 July, Research Councils UK announced that they were also introducing Open Access requirements. ${ }^{13}$ As it has been implemented, RCUK offers funding to researchintensive universities to disseminate their funded research outputs as Gold OA outputs. ${ }^{14}$ In the first 3 years of activity, UCL (University College London) exceeded the targets which RCUK had set. The vast majority of papers made Open Access were Gold, supported by RCUK funding.

\begin{tabular}{|l|l|l|l|}
\hline Year & $\begin{array}{l}\text { RCUK target for } \\
\text { OA papers }\end{array}$ & $\begin{array}{l}\text { UCL result for } \\
\text { OA papers }\end{array}$ & $\begin{array}{l}\% \\
\text { compliance }\end{array}$ \\
\hline Year 1 & 693 & 797 & $115 \%$ \\
\hline Year 2 & 815 & 963 & $118 \%$ \\
\hline Year 3 & 924 & 991 & $107 \%$ \\
\hline $\begin{array}{l}\text { Year 4 } \\
\text { (Apr 16-Mar 17) }\end{array}$ & 1090 & 798 & $\begin{array}{l}65 \% \\
\text { (to 0ct 17 } \\
2016)\end{array}$ \\
\hline
\end{tabular}

In Europe, the Dutch have also taken a similar strong line on Gold Open Access. 'This gold standard open access is the route the Netherlands has been pursuing aggressively at home, and which it has pledged

UCL: https://Mww.ucl.ac.uklibrary/open-access/research-funders; last accessed 3/1/177.

UCL: hitps://Www.ucl.ac.uk/news/news-articles/0216/17022016-ucl-excels-EU-research-funding; last accessed 3/1117

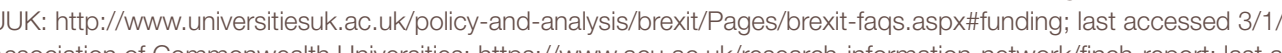

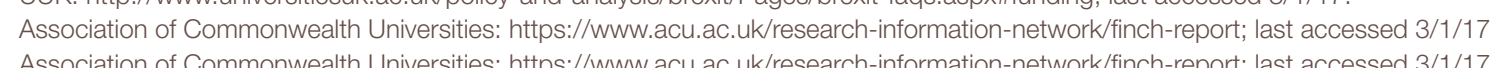

Research Councils UK: http://www.rcuk.ac.uk/research/openaccess/ for the latest iteration of the RCUK Open Access policy; last accessed 
to steer the whole of the EU towards during its ... presidency. ${ }^{\prime}$ In fact, a 2016 study ${ }^{16}$ found that $5 \mathrm{EU}$ countries want to abandon the traditional subscription model and move to Gold Open Access dissemination: the Netherlands, Hungary, Romania, Sweden and the UK. Clearly, the UK has contributed to this debate, a contribution not solely shaped by the EU.

In the UK, the recent HEFCE mandate for Open Access to support the Research Excellence Framework (REF) 2020 is already being very influential in shaping attitudes to OA dissemination in universities. ${ }^{17}$ The REF has enormous influence since the results determine the selective annual allocation of quality-related (QR) grant distribution from the Higher Education Funding Councils. There is every chance that REF OA compliance, rather than the Finch review or even the RCUK OA mandate, will be a game changer for the development of OA in the UK going forward.

\section{European Copyright reform}

The European Union is currently engaged in what we believe to be the final stages of copyright reform proposals. In Europe, a number of organisations are taking a leading role in supporting demands for academic-friendly copyright reform, bodies such as LIBER (Association of European Research Libraries) and LERU (League of European Research Universities). ${ }^{18}$ For these organisations, the crux of the matter is the need to modernise copyright legislation for the digital age. Their case is focussed on the need for an Exception for Text and Data Mining (TDM) to be enshrined in the new legislation. ${ }^{19}$ Text and data mining is the process of deriving information from machine-read material. It works by copying large quantities of material, extracting the data, and recombining it to identify patterns. Copyright legislation is involved in the discussion because of the act of copying. For a digital future, let alone an Open Access future, TDM is an essential tool. Researchers will want to mine content which is both Open Access and material which is available from commercial suppliers, where copyright has typically be assigned to the publisher. LIBER and LERU assert that 'the right to read is the right to mine'; and that all content, to which researchers have lega access, should be open for TDM. There are also legal barriers which restrict researchers' abilities to mine the open web. This legal uncertainly hampers research and discoveries, which would act as a foundation for innovation and income generation, creating new jobs for the European economy. It is vital that the draft copyright reform proposal ${ }^{20}$ currently offered by the Commission embraces all these requirements.

When the UK leaves the EU, where will it stand in relation to the new Directive? There are two issues to consider. There are already copyright-friendly regimes in operation around the world: the USA, Asia, Canada and the UK, for example. In the UK, the Hargreaves review of UK copyright frameworks allows an Exception for TDM, but for non-commercial purposes only. ${ }^{21}$ In this form, this mirrors the current proposal from the EU Commission. For the UK, however, a major issue would be how it should react if the final version of the EU reform package is vastly different from the UK's current offering. If the EU adopts such advanced and improved proposals before Brexit, it is possible/likely that the EU stipulations would be carried over into UK law, unless they are rejected by Parliament or the courts. If, however, the EU reform package is delayed further and not adopted until after Brexit, how will the UK react? Given research collaborations between
European universities, it would be unacceptable for the UK to have less generous arrangements for TDM than other European partners. This represents a challenge for the UK going forward.

New publishing models

Open Access allows new approaches to scholarly publishing. In the UK, there is a growing amount of interest in the creation of Open Access publishing platforms, often linked to institutional university libraries. interest in the creation of Open Access publishing platforms, often linked to institutional university libraries. Open Science/Open Scholarship agenda, UCL Press will seek to make its published outputs available to a global audience, irrespective of the ability to pay, because UCL believes that this is the best way to tackle global 'Grand Challenges'23 such as poverty, disease, hunger.

The Press focuses its publishing activity on scholarly monographs, scholarly editions, textbooks, edited collections and journals. After 18 months of activity, the Press can report considerable success. It has now
surpassed 200,000 downloads for its published outputs. On the website, 43 titles have been published surpassed 200,000 downloads for its published outputs. On the website, 43 titles have been published Open Access, with the university meeting the publishing costs for UCL authors once the submissions have been peer reviewed. For external authors, a Book Publication Charge is levied, which is £5000 for books up to 100,000 words. ${ }^{24}$ There is a waiver scheme for a number of selected non- $U C L$ authors. The waiver scheme demonstrates UCL's commitment to Open Access publishing and its awareness of the challenges faced by non-funded authors. The UCL Press model is by no means unique to UCL in Europe. However, it is fair to say that institutional Open Access publishing in the UK is fast-growing and self-seeding, and not yet largely driven by other European developments. In this context, Brexit will neither damage nor encourage this home-grown plant to flower.

\section{Open Science}

One area in which the European Union has taken a clear leadership role is Open Science. This role was developed under the innovative Dutch presidency of the Union in 2016. The Open Science Conference in Amsterdam in May of that year, and the Council Open Science Conclusions, point to real leadership which the EU has offered..$^{25}$ The Conclusions have strong ambitions for Open Access.

\section{The Council}

AGREES to further promote the mainstreaming of open access to scientific publications by continuing to support a transition to immediate open access as the default by 2020, using the various models possible and in a cost-effective way, without embargoes or with as short as possible embargoes, and without financia and legal barriers, taking into account the diversity in research systems and disciplines, and that open access to scientific publications should be achieved in full observance of the principle that no researcher should be prevented from publishing: INVITES the Commission, Member States and relevant stakeholders, including research funding organisations, to catalyse this transition; and STRESSES the importance of clarity in scientific publishing agreements.'

\footnotetext{
uk/ucl-press/publish, last accessed 3/1/17 UCL: https://Www.ucl.ac.uk/grand-challenges; last accessed 31/1/177.
UCL Press: http://www.ucl.ac.uk/ucl-press/(jublish; last accessed 3/1/17. 
Full Open Access by 2020 is a very ambitious vision. As a member of the EU, the UK is committed to support this objective. After Brexit, depending on the nature of the future relationship between the $\mathrm{EU}$ and the UK, the United Kingdom probably will not be mandatorily subject to this requirement going forward. In the UK itself, there is no current equivalent mandate for $100 \%$ OA compliance by 2020 . The nearest directive is probably the HEFCE requirement for the Research Excellence Framework, also 2020. However, not all research produced in the UK is submitted to the REF. The EU ambition for OA, therefore, is more expansive than the public position in the UK. It has to be said, however, that the UK position on 2020 may be more realistic in terms of the ability to attain the stated objective.

One of the major early deliverables from the Open Science agenda is a bold vision for a European Open Science Cloud (EOSC) of research objects. The Commission has appointed a High Level Expert Group (HLEG) to advise on progress in the Cloud, which is a metaphor for an Internet of data, and the HLEG has recently released its Report. ${ }^{26}$ I was honoured to be a member of the Group that compiled this document. One of the major observations it contains is that the majority of challenges to reach a functional EOSC are 'social rather than technical'. Another major finding is that there is an 'alarming shortage of data experts both globally and in the European Union'. The Report also determines that the technical components needed to create a first generation EOSC are largely in existence already, but that they are 'lost in fragmentation and spread over 28 member states and across different communities'. There is a real challenge facing the UK, and indeed Europe, if the UK is not a member of the EOSC going forward. Research is global; it does not stop at national boundaries. The UK will suffer if its research data is not visible as part of this European collaboration. Europe, and indeed research communities across the globe, will also be the poorer if they cannot seamlessly access UK research outputs alongside other European findings.

\subsection{CONCLUSION}

The argument of this paper is that, no matter what sort of relationship the UK develops with the European Union post Brexit, Brexit itself poses not only challenges but also presents opportunities. The Mayor of London has written about a new agenda. The UK has already achieved much in the field of Open Access policy and infrastructure, much without direct dependence on European parallels. Indeed, new models of scholarly publishing, developing quickly in the UK, have the power to redefine how the outputs of research are shared and made available.

Nonetheless, there remain challenges. Loss of funding from bodies such as the European Research Council and programmes like Horizon 2020 would have a detrimental effect on the amount of research which the UK can undertake. And while Brexit may give the UK freedom from European jurisdiction, that must not lead to isolation. The European Union has taken a major leadership role in propounding Open Science approaches. It would be a disaster for the UK, were leadership in this important global agenda to be lost in a country that has cut itself off from wider partnerships and collaborations.

This project has received funding from the European Union's Horizon 2020 research and innovation programme under grant agreement No 654139. 